\title{
Nutritional Profile of Triathletes in a Week before a National Competition
}

\author{
Nayara F. Cunha, Jhessika F. Silva, Tatienne N. F. Costa* \\ Nutrição, Universidade Federal do Tocantins, Palmas, Brazil
}

\begin{abstract}
The aim of this study was to evaluate the nutritional profile of triathletes in the week prior to a triathlon national event. Study participants were 08 triathletes of both sexes, who carried out the 10th edition of SESC-Triathlon National Circuit, Sprint and Olympic, in the city of Palmas, Tocantins, Brazil. The consumption of energy and macronutrients were evaluated by self-report of 03 food records in the previous week of the national competition, in which two should be conducted during the week and on days that had at least one of the modes of triathlon and the third nutrition survey must necessarily be filled in the day before the competition. The body mass found was $72.7 \mathrm{~kg} \pm 11.1 \mathrm{~kg}$. The triathletes energy intake was adequate $\left(31.8 \pm 5.5 \mathrm{kcal} . \mathrm{kg}^{-1} /\right.$ day $)$, whereas there was a low carbohydrate intake to $75 \%$ of participants, with an average consumption of $4.6 \pm 0.9 \mathrm{~g} \cdot \mathrm{kg}^{-1} / \mathrm{day}$. The protein intake remained within the recommendation

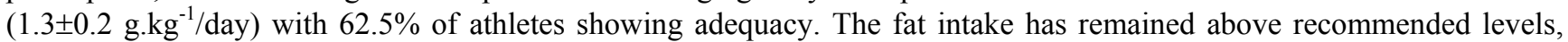
with an average intake of $2.9 \pm 0.5 \mathrm{~g} \cdot \mathrm{kg}^{-1} / \mathrm{day}$. The elevated intake of this nutrient was seen occur in $37.5 \%$ of participants. It could be concluded that athletes have nutritional inadequacies and that consumption of carbohydrate in the days preceding the exercise was not correlated to the competition time for the athletes evaluated.
\end{abstract}

Keywords Pre-competition, Triathletes, Nutritionalprofile

\section{Introduction}

The triathlon is a sport that had its beginning in 1978, with the first Ironman race being held in Hawaii, with the participation of 15 competitors [1]. This sport consists of a continuous and sequential activity of swimming, cycling and running, which can be classified into four main types of evidence: Sprint, Olympic, Half Ironman and Ironman, which differ in relation to the distance traveled [2]. Metabolically, it is a sport that emphasizes aerobic bio-energetic system and requires a high calorie cost, reaching in test as the Ironman, over $8000 \mathrm{kcal}$ values [3], reaching even $11000 \mathrm{kcal}$ [4].

For the realization of this sport, there is a necessity of intensive training, since they are three different modes, which in practice account for approximately 20 hours a week of training, performed mostly with more than one session per day [2]. In this sense, nutrition plays an important role in the training phase but also in the competitive period, through the consumption of sufficient amounts of energy and macronutrients. This food intake should contain high carbohydrate content, particularly in the week before the competition, in order to guarantee

* Corresponding author:

tatienneneder@uft.edu.br (Tatienne N. F. Costa)

Published online at http://journal.sapub.org/sports

Copyright (C) 2015 Scientific \& Academic Publishing. All Rights Reserved satisfactory stocks of muscle and liver glycogen at the time of the race. Because of the importance of nutrition in the performance of athletes, this study aimed to evaluate the nutritional status of triathletes in the previous week to a national triathlon competition and the correlation between the consumption of carbohydrates and performance.

\section{Methodology}

\subsection{Experimental Design}

This study was conducted with triathletes, participants in the 10th edition of the SESC-Triathlon National Circuit, held in Palmas, Tocantins State, Brazil, in August, in the year 2014. Initially there was a contact with the responsible team Triathlon city of Palmas, Marcão Triathlon Club Sports Consulting (MTC) in order to verify their interest in collaborating in the survey. An authorization form was then signed by the responsible.

Subsequent to this step, a survey was done of all athletes belonging to this team and who were enrolled in this sporting event. As criterion of inclusion, athletes should regularly train the three modes of triathlon competition and perform all of them, without turns with another participant.

The athletes were informed about the objectives and experimental study procedures and, with interest, they signed a Term of Free and Clear Consent, previously approved by the Ethics Committee in Research with Human Beings of the 
Federal University of Tocantins (UFT).

The testing time of each athlete was recorded by the researchers.

\subsection{Subjects}

The sample consisted of 16 amateur triathletes, of both sexes, belonging to the team MTC Sports Consulting, who participated in the 10th edition of the SESC-Triathlon National Circuit Short type (750m swimming, 20km cycling and running $5 \mathrm{~km})$ or Olympic $(1500 \mathrm{~m}$ swimming, $40 \mathrm{~km}$ cycling and $10 \mathrm{~km}$ running).

\subsection{Nutritional Profile}

The assessment of nutritional profile in the week before the competition was made by the self-fulfillment of three food records, of which two should be conducted during the week and on days that were practiced at least one of the modes of triathlon. The third food investigation should necessarily be completed the day before the competition.

Subjects were initially instructed concerned the correct filling of food report, through illustrative figures of the main portion sizes and foods consumed.

The food intake, expressed in home measurements were converted to grams and/or milliliters, for further evaluation of energy intake and macronutrient, by nutritional calculation program Dietwin.

It was adopted as reference for energy consumption and macronutrient the values recommended by the Brazilian Society of Medicine's Exercise and Sport [5], expressed in kcal. $\mathrm{kg}^{-1} /$ day and $\mathrm{g} . \mathrm{kg}^{-1} /$ day, respectively.

Body weight was measured by an electronic scale with a capacity of $180 \mathrm{~kg}$, with accuracy of $100 \mathrm{~g}$ (personal scale 180. Filizola, São Paulo, Brazil). For quantification of body weight, the individual should be with the usual attire for training, bare and unadorned. The evaluated were placed standing, remaining facing the measurement scale of the scale, with arms at your sides and look at a fixed point in front.

From the completed food records could also evaluate the number of meals a day.

Data on food consumption and frequency of meals were expressed as average and standard deviation and carbohydrate consumption variables and competition time were submitted to the Shapiro-Wilk test for normality. The correlation between them was conducted by the Pearson test. The probability of containing the error type 1 was 0.05 . The statistics program used was BioEstat 5.3, free distribution.

\section{Results}

Among the 16 athletes interested in attending the study, only 08 athletes were included in the analysis because, the others did not deliver the food record, making it impossible thus the evaluation. Between the participants, the found body weight was $72.7 \mathrm{~kg} \pm 11.1 \mathrm{~kg}$.

Most (75\%) were men between 27 and 49 years of age
(33.3 \pm 8.47$)$ and minority women ( $25 \%)$, between 29 and 43 years $(36.0 \pm 9.9)$. Of the total, only 01 athletes competed proof of Olympic type, with the remainder $(n=7)$ of the Sprint race competitors.

The energetic intake of triathletes was $31.8 \pm 5.5$ $\mathrm{kcal} . \mathrm{kg}^{-1} / \mathrm{day}$, showing up within the recommended intake. Moreover, the carbohydrate intake is presented below recommendation for $75 \%$ of participants, as shown in Table 1. It was also possible to observe a noticeable interindividual variability for this macronutrient, with a minimum consumption value of 3.6 g. kg kg-1/day and a maximum of $6.4 \mathrm{~g} . \mathrm{kg}^{-1} /$ day. Protein intake remained within the recommendation, obtaining an average consumption $1.3 \pm 0.2$ g. $\mathrm{kg}^{-1} /$ day, of the athletes presented an adequate intake. The fat intake remained above recommended levels, with an average intake of $2.9 \pm 0.5 \mathrm{~g} . \mathrm{kg}^{-1} /$ day. High intake of this nutrient was seen occur in $37.5 \%$ of the participants.

Table 1. Energy and macronutrient ingestion by triathletes in the week preceding the competition

\begin{tabular}{|c|c|c|}
\hline Energy/Macronutrients & Consumption & $\begin{array}{c}\text { Recommended } \\
\text { Value* }\end{array}$ \\
\hline Calories (Kcal/day) & $2308.6 \pm 743.2$ & - \\
\hline Calories (kcal. $\mathrm{kg}^{-1} /$ day) & $31.8 \pm 5.5$ & $30.0-\quad 50.0$ \\
\hline Carbohydrate (g/day) & $332.6 \pm 109.5$ & - \\
\hline Carbohydrate(g.kg-1/day) & $4.6 \pm 0.9$ & $5.0-10.0$ \\
\hline Protein (g/day) & $91.7 \pm 32.6$ & - \\
\hline Protein(g.kg ${ }^{-1} /$ day $)$ & $1.3 \pm 0.2$ & $1.2-1.6$ \\
\hline Fat (g/day) & $68.5 \pm 35.1$ & - \\
\hline Fat (g/kg/day) & $2.9 \pm 0.5$ & 1,0 \\
\hline
\end{tabular}

*Brazilian Society of Medicine's Exercise and Sport, SBME (2009)

The number of meals $6.2 \pm 1.7$. For evaluating the competition time and the correlation between it and the carbohydrate intake was excluded from the analysis the athlete who competed at Olympic event, given the double distance of the proof in respect of Sprint. The competition time was of $81.0 \pm 10.2$ minutes. There was no correlation between carbohydrate intake and time test for the evaluated athletes $(\mathrm{r}=0.14 ; \mathrm{p}=0.77)$.

\section{Discussion}

In athletes, strenuous physical training routine induces considerable changes in nutritional needs, which must therefore be properly planned in order to obtain improvements in athletic performance. Regardless of the sport, athletes should prioritize the adequate intake of energy for weight maintenance and body composition conducive to the sport practiced, optimization of performance and benefits of training and maintenance of health [6], that can become committed to energy imbalance condition.

A varied diet that emphasizes foods rich in nutrients and fluids and is adjusted to the daily training routine of the athlete can avoid extreme dietary behavior as severe energy 
restriction and reduced variety of foods [2].

Although the current sports nutrition guides are not specific to each sport $[5,6]$, it is known that each has its own peculiarities, and these has been closely related to their own energy demands imposed by each activity. So, when considering that the energy expenditure for different types of exercise is dependent on factors such as duration, intensity, frequency, athlete's gender and prior nutritional status, it is evident that the daily energy demands are also different [6]. Hill and Davies (2001) [7] evaluated the energy expenditure of an Austrian marathoner for two weeks in held ultra-marathon and the average was $6321.0 \mathrm{kcal} /$ day, a significantly lower value than that found in basketball juniors players $(4210.0 \pm 789.0 \mathrm{kcal})$ during a competition [8]. Extreme energy expenditure have been carried out in triathletes, as in the study of Kimber, et al. (2002) [3], which found during the cycling and running an Ironman competition a calorie expenditure of $10.036 \pm 931 \mathrm{kcal} \mathrm{e}$ $8570 \pm 1.014 \mathrm{kcal}$, for men and women, respectively. Similarly, Barrero, et al. (2015) [4], estimated the energy expenditure of $11009.0 \pm 664.0 \mathrm{kcal}$ for triathletes in an Ironman competition.

In the present study, although the daily energy expenditure or resulting from training have not been measured, important differences between studies allow us to make some comparisons. First, the above studies were conducted in Ironman competition, different from our study, which, in addition to being carried out on training days, was executed, mostly by athletes practicing Sprint, which is the shortest ranking Triathlon. Despite the lack in the literature on energy expenditure in training and/or evidence of Sprint kind, the fact that its distance is well below the Ironman, it is expected that energy expenditure is also significantly lower. In a previous study [9] in which we estimate the energy cost of two days of training a triathlete who also participated in this study, the calorie expended was $834 \mathrm{kcal}$ and $361 \mathrm{kcal}$, much lower than the values found in the mentioned studies. Thus, although we have not enough data to assess whether there was energy deficit in the evaluated athletes, we believe that if they were in imbalance, it is likely to be much less significant when compared to Ironman athletes who require more caloric diets in order to compensate for their high energy expenditure.

In this sense, the more energy is spent on a given activity, the more calories through diet are necessary for the daily energy balance is maintained. However, there are significant energy deficit reports $(7365 \pm 1286 \mathrm{kcal})$ in triathletes during a competitive event [4].

In our study, although the daily energy intake has been adequate, it had close to the minimum recommended value. A possible explanation for this finding may be the low carbohydrate intake among athletes, contrary to study of Nogueira and Costa (2004) [10]. There are other aspects elucidated in the literature, such as the lack of opportunities for evidence as Triathlon Sprint and Olympic for proper carbohydrate intake, residual fatigue associated with training, reduced appetite after intense training sessions, inadequate meal plan, training routines with more than one session per day, frequently common in triathlon [2], as well as gastrointestinal discomfort during exercise [11], which can limit the energy/glycidic intake of the athlete [2].

Thus, efforts should be directed to the maintenance of energy balance, because of its important role in preventing muscle fatigue, immunosuppression [12], menstrual disorder, loss of bone mass in female athletes [13] and increased risk of injury [14].

Changing eating habits of athletes like the increase in the number of meals a day ( $>6$ /day) with the consumption of high energy density foodscan be considered a good nutritional strategy to achieve the nutritional needs, especially in athletes in intense training phase or making multiple training sessions daily [6], as pointed out by Nogueira and Costa (2004) [10], who found a frequency of 4-5 meals a day in the evaluated triathletes. Although the athletes evaluated in this study have submitted $6.2 \pm 1.7$ meals a day, when analyzing the dietary pattern of the athletes, it was observed that some meals were composed by low caloric density and carbohydrate foods (fruits and supplements such as BCAA, creatine and whey protein). Thus, it should stimulate not only increasing the number of meals, but also the inclusion of foods which enable the athlete to achieve their nutritional requirements.

The role of carbohydrates as an energy source for skeletal muscle initially emerged from the important study of Christensen and Hansen (1939) [15], to show that athletes exercised longer after several days with high carbohydrate diet when compared to the same period being fed with low carbohydrate diet. However, the mechanisms involved in this association came to be elucidated only almost 30 years later, with the elegant study of Bergström and Hultman [16] in 1966, that, through muscle biopsy, found that when consuming high carbohydrate diet after days of strenuous exercise with carbohydrate deprivation, athletes had significantly increased their muscle glycogen stores $(170 \%)$ when compared to normal values. Although this study has contributed to the advancement in the science of sports nutrition, subsequent studies have shown that athletes can achieve high muscle glycogen concentrations without the need for the depletion phase of the same [17].

The relationship between high intake of carbohydrates, glycogen content, blood glucose maintenance and improvement of the performance of resistance exercise has been well documented [18, 19], and these benefits possibly have directed the classic nutrition consensus sports force for recommending diets that are high in carbohydrates for athletes $[5,6]$.

Unlike the findings of some previous studies [20-22] we do not find correlation between carbohydrate consumption in the week prior to the competition and performance. The lack of correlation may be associated with shorter duration of exercise in our investigation (81 minutes) compared to previous studies ( $>90$ minutes) [20-22]. Considering that the carbohydrate intake period between studies (3-7 days) was similar to ours, it is likely that the time of the competition of 
this study has been insufficient to promote a critical state of muscle glycogen content that could limit the athletes' performance. Furthermore, the aforementioned studies $[20,21]$ were performed only on the treadmill to exhaustion ( $70 \% \mathrm{VO}_{2}$ max.), distinct condition of this study and with a higher carbohydrate intake (464g/day) [22].

Contrary to traditional guides of sports nutrition, a relatively new concept called training low compete high has been investigated by some authors. According to this strategy, the athletes train with low and compete with high availability of glycogen/carbohydrate [23]. To reduce the availability of this nutrient during training, the athlete has several nutritional maneuvers such as training after an overnight fast, hold two training sessions a day, with the second session being low in carbohydrates, among others (see review Burke, 2010) [23]. Adjustments as increased metabolic activity of enzymes involved in energy metabolism and mitochondrial biogenesis [24], as well as increased lipid oxidation [25] have been demonstrated, in this condition, occur. Also, the low muscle glycogen content stimulates mitochondrial biogenesis by increased activation of 5'AMP-activated protein kinase (AMPK) [26-28], as well as by the increased expression of nuclear respiratory factor 1 (NRF-1) transcription factor that, when active, it stimulates the transcription of genes encoding mitochondrial proteins [29].

Although the chronic effects of training low compete high in the adaptive response to muscle appear to be promising, studies on the effect of this strategy on improving performance are still inconclusive and controversial [25, 26]. Thus, individuality must be taken into consideration when choosing the best eating behavior and tested from training, thus verifying the success or failure of a given nutritional intervention.

The triathlon, for being a sport in which athletes regularly conduct two training sessions of different types on the same day, could illustrate that, in practice, some athletes already use this strategy. However, experimental design differences are worth mentioning. We conducted this work with individuals trained in triathlon, mostly Sprint type, unlike previous studies that evaluated trained cyclists [25] and untrained individuals undergoingknee extensor exercise [24]. State training and modality of sports are factors known to promote different metabolic responses. Furthermore, the short recovery period (1-2 hours) [24, 25] between the first and second day of the training session is not consistent with the practice of many athletes. It is our understanding that the triathletes of this study, for example, usually train at different times of day. Finally, the carbohydrate intake offered in some studies was significantly higher $\left(8 \mathrm{~g} . \mathrm{kg}^{-1} /\right.$ day $)$ [25] when comparing to ours $\left(4.6 \pm 0.9\right.$ g. $\mathrm{kg}^{-1} /$ day $)$, which could induce us to think that athletes of this research would be in low-carbohydrate availability condition for the completion of the exercise. However, as reported by Hawley (2014) [30], currently missing data concerning the energy expenditure of different endurance training and thus, discuss the degree of depletion of glycogen or the restriction availability of carbohydrate that is required to achieve the metabolic adaptations It seems to be irrelevant, since we lack information about the real demands of carbohydrate in the different training sessions. Another limitation is the uncertainty that the carbohydrate content offered to participants was in fact consumed, since many studies do not realize this kind of food control [25].

In sports, in general, the protein needs increase as the type of exercise performed, intensity, duration and frequency [5] and its deficiency may involve injury in training capacity, especially in the recovery phase [31].

The protein needs of athletes involved in endurance sports have received increased attention due to their participation in the repair of muscle microlesions related to the sports practice, with muscle damage reports in triathletes during competition and recovery [32]. Similar to resistance exercise, studies have shown that protein intake can also increase muscle protein synthesis rates after exercise prolonged and strenuous endurance [33]. Consequently, sports nutrition guides have recommended an increased protein intake for athletes, regardless of the type of exercise. In our study, the protein consumption of triathletes showed up within the recommendations to athletes engaged in endurance. Given that the rate of protein synthesis in several studies lasts some hours (0-6horas) [33] after the endurance exercise, it is essential that athletes have not only adequate protein intake immediately after exercise, but also a satisfactory total intake of protein distributed throughout the day, as has been recently suggested for athletes engaged in strength training $[34,35]$.

Interestingly, research has also suggested that following endurance exercises that promote muscle damage, masters athletes have slower recovery rates compared to younger, equally well trained, response that, according to Doering, et al. (2015) [36] may be due to losses in muscle remodeling mechanisms of masters athletes. In our study, the majority of triathletes, of both sexes, belonged to this classification, but there is no way to say whether the amount consumed by the participants was sufficient for a complete muscle repair or if they need to consume values close to the maximum recommended limit, because we have not done this type of analysis. Also, so far we do not have daily recommendation for protein for athletes engaged in endurance sports, according to age.

Thus, future studies are needed to first assess the rate of protein synthesis for longer periods in endurance athletes ( $>24$ hours) as well as the effect of different amounts of protein in muscle repair daily these athletes.

A limitation of this study was the small number of individuals assessed, since it is known that, especially among athletes, there are considerable variations in the duration of training, the hours of training, as well their own food preferences in the pre, during and post-exercise, factors that potentially affect the food and therefore the consumption of energy and macronutrients. Therefore, future studies with larger numbers of evaluated and concurrently investigate the nutritional profile, caloric expenditure and substrate 
oxidation in the different sessions and phases of training are required, so that they can trace most effective nutritional strategies.

\section{Conclusions}

In conclusion, the triathlon athletes practicing of this study showed nutritional inadequacies in the week before the competition and there was no correlation between the carbohydrate consumed in the days prior to the competition and performance.

\section{ACKNOWLEDGEMENTS}

The authors would like to thank the study participants for their commitment throughout the work. The study was designed by Costa, T.N.F., and Cunha, N.F.; data were collected and analyzed by Costa, T.N.F., Cunha, N.F., and Silva, J.F.; data interpretation and manuscript preparation were undertaken by Costa, T.N.F., Cunha, N.F., and Silva, J.F. None of the authors had a financial or personal conflict to finterest to declare and all authors approved the final version of the paper.

\section{REFERENCES}

[1] LAURSEN, P.B., 2011, Long distance triathlon: demands, preparation and performance., J. Human. Sport. Exerc. 6(2), 247-263.

[2] Bentley, D.J., Cox, G.R., Green, D., and Laursen, P.B., 2008, Maximising performance in triathlon: applied physiological and nutritional aspects of eliteand non-elite competitions., J.Sci. Med. Sport.,11(4), 407-416.

[3] Kimber, N.E., Ross, J.J., Mason, S.L., and Speedy, D.B., 2002, Energy balance during an ironman triathlon in male andfemale triathletes., Int. J. Sport.Nutr. Exerc. Metab., 12(1), 47-62.

[4] Barrero, A., Erola, P., Bescós, R., 2015, Energy balance of triathletes duringan ultra-endurance event., Nutrients; 7, 209-222.

[5] BrazilianSocietyofMedicine'sExerciseand Sport (SBME)., Hernandez, A.J., andNahas, R.M., 2009, Dietary changes, water replacement, food supplements and drugs: evidence of ergogenic action and potential health risks., Rev. Bras. Med. Esporte., 15(3), 3-12.

[6] American College of Sports Medicine Position Stand (ACSM), 2009, Nutrition and Athletic Performance., Med. Sci. Sports. Exerc., 41(3), 709-731.

[7] Hill, R.J., and Davies P. S., 2001, Energy expenditure during 2 wk of an ultra-endurance run around Australia, Med. Sci. Sports Exerc.; 33(1),148-51.

[8] Silva, A.M., Santos, D.A., Matias, C.N., Minderico, C.S., Schoeller, D.A., and Sardinha, L.B., 2013, Total energy expenditure assessment in elite junior basketball players: avalidation study using doubly labeled water., J. Strength. Cond. Res., 27(7), 1920-1927.

[9] Oliveira, K.R., Ferreira, N.C., Vechiato, T., Costa, T.N.F., 2015, Ingestãocalóricadiária de triatletaemdias de treino com diferentedispêndio energético: Relato de caso,. V Congresso de EducaçãoFísica do Vale do São Francisco, 138.

[10] Nogueira, J.A.D., Costa, T.H.M., 2004, Nutrient intake and eating habits of triathletes on a brazilian diet., Int. J. Sport. Nutr. Exerc. Metab., 14, 684-97.

[11] Oliveira, E.P., and Burini, R.C., 2014, Carbohydratedependent, exercise induced gastrointestinal distress., Nutrients, 6, 4191-4199.

[12] Lancaster, G.I., Khan, Q., Drysdale, P.T., Wallace, F., Jeukendrup, A.E., Drayson, M.T., and Gleeson, M., 2005, Effect of prolonged exercise and carbohydrate ingestion on type 1 and type $2 \mathrm{~T}$ lymphocyte distribution and intracellular cytokine production in humans., J. Appl. Physiol., 98(2), 565-571.

[13] Pollock, N., Grogan, C., Perry, M., Pedlar, C., Cooke, K., Morrissey, D., and Dimitriou, L., 2010, Bone-mineral density and otherfeatures of the female athlete triad in elite endurance runners: Alongitudinal and cross-sectional observational study., Int. J. Sport. Nutr. Exerc. Metab., 20, 418-426.

[14] Gerlach, K.E., Burton, H.W., Dorn, J.M., Leddy, J.J., and Horvath, P.J., 2008, Fat intake and injury female runners., J. Int. Soc. Sports. Nutr., 5(1), 1-8.

[15] Christensen EH, Hansen O., 1939, ZurMethodik der respiratorischen Quotient-Bestimmungen in Ruheandbei Arbeit., 81, 137-171.

[16] Bergström, J., and Hultman, E., 1966, Muscle glycogen synthesis after exercise: an enhancing factor localized to the muscle cell in man., Nature 20, 309-310.

[17] Sherman, W.M., Costill, D.L., Fink, W.J., and Miller, J. M., 1981, Effect of exercise-diet manipulation on muscle glycogen and its subsequent utilization during performance., Int. J. Sports Med., 2(2), 114-8.

[18] Casey, A., Mann, R., Banister, K., Fox, J., Morris, PG., Macdonald, I.A., and Greenhaff, P.L., 2000, Effect of carbohydrate ingestion on glycogen resynthesis in human liver and skeletal muscle, measured by (13)C MRS., Am. J. Physiol. Endocrinol. Metab., 278(1), 65-75.

[19] Hargreaves, M., Hawley, J.A., and Jeukendrup, A., 2004, Pre-exercise carbohydrate and fat ingestion; Effects on metabolism and performance, J. Sports. Sci., 22(1), 31-38.

[20] Brewer, J., Williams, C., Patton, A., 1988, The influence of high carbohydrate diets on endurance running performance., Eur. J. Appl. Physiol. Occup. Physiol., 57(6), 698-706.

[21] Galbo, H., Holst, J.J. and Christensen, N.J., 1979, The effect of different diets and of insulin on the hormonal response to prolonged exercise, ActaPhysiol Scand., 107(1):19-32.

[22] Walker, J.L., Heigenhauser, G.J.F., Hultman, E., and Spriet, L. L., 2000, Dietary carbohydrate, muscle glycogen content, and endurance performance in well-trained women., J Appl Physiol, 88: 2151-2158.

[23] Burke, L.M., 2010, Fueling strategies to optimize performance: training high or training low?., Scand. J. 
Med.Sci. Sports., 20(2), 48-58.

[24] Hansen, A.K., Fischer, C.P., Plomgaard, P., Andersen, J.L., Saltin, B., and Pedersen, B.K., 2005, Skeletal muscle adaptation: training twice every second day vs. training once daily., J. Appl. Physiol., 98, 93-99.

[25] Hulston, C.J., Venables, M.C., Mann, C.H., Martin, C., Philp, A., Baar, $\mathrm{K}$ and Jeukendrup, A.E., 2010, Training with low muscle glycogen enhances fat metabolism in well-trained cyclists., Med. Sci. Sports Exerc., 42(11), 2046-55.

[26] Yeo, W.K., Paton, C.D., Garnham, A.P., Burke, L.M., Carey, A.L and Hawley, J.A., 208,Skeletal muscle adaptation and performance responses to once a day versus twice every second day endurance training regimens., J. Appl. Physiol., $105,1462-70$

[27] McBride, A., Ghilagaber, S., Nikolaev, A., and Hardie, D.G., 2009, The glycogen-binding domain on the AMPK subunit allows the kinase to act as a glycogen sensor., Cell Metab., 9, 23-34.

[28] Psilander, N., Frank, P., Flockhart, M., and Sahlin, K., 2013, Exercise with low glycogen increases PGC-1a gene expression in human skeletal muscle., Eur. J. Appl. Physiol., 113(4), 951-1963.

[29] Hawley, J.A., and Holloszy, J., 2009, Exercise: It's the real thing!., Nutr. Rev., 67(3), 172-178.
[30] Hawley, J.A., 2014, Manipulating carbohydrate availability to promote training adaptation., Sports Sci. Exchange., 27(2), 134, 1-7.

[31] Cabral, C.A.C., Rosado, G.P., Silva, C.H.O., and Marins, J.C.B., 2006, Diagnosis of the nutritional status of the weight lifting permanent olympic team athletes of the Brazilian olympic committee (COB)., Rev. Bras. Med. Esporte., 12(6), 345-350

[32] Neubauer, O., König., D., and Wagner, K.H., 2008, Recovery after an Ironman triathlon: sustained inflammatory responses and muscular stress., Eur. J. Appl. Physiol., 104(3), 417-26.

[33] Levenhagen, D.K, Carr, C, Carlson, M.G, Maron, D.J, Borel, M.J, Flakoll,P.J., 2002, Postexercise protein intake enhances whole-body and leg protein accretion in humans., Med Sci Sports Exerc., 34(5),828-37.

[34] Schoenfeld, B.J, Aragon, A. A, Krieger, J.W., 2013, The effect of protein timing on muscle strength and hypertrophy: a meta-analysis., J. Int. Soc. Sports Nutr., 10(53), 2-13.

[35] Phillips, S.M., 2014, A Brief Review of Critical Processes in Exercise-Induced Muscular Hypertrophy., Sports Med., 44(1), 71-77.

[36] Doering, T.M., Reaburn, P.R., Phillips, S.M and Jenkins, D.G., 2015, Post-Exercise Dietary Protein Strategies to Maximize Skeletal Muscle Repair and Remodeling in Masters Endurance Athletes: A Review., Int. J. Sport. Nutr. Exerc. Metab. 